\title{
Association of Physical Activity and Handgrip Strength among Korean Elderly
}

\author{
Seong-Hun Kim', Bee-Oh Lim', Keun-Ok An² \\ ${ }^{1}$ Chung-Ang University, Seoul, Korea \\ ${ }^{2}$ Korea National University of Transportation, Chungju, Korea
}

Received: October 11, 2019
Accepted: October 25, 2019
Published online: October 31, 2019
Keywords:
Handgrip Strength
Korea National Health and
Nutrition Examination
Survey(KNHNES)
Older Adults
Physical Activity
Check for
updates

\section{ABSTRACT}

OBJECTIVES The purpose of this study was to investigate the association of physical activity and the handgrip strength in the elderly.

METHODS Using the 7th Korea National Health and Nutrition Survey (KNHANES) 2017 dataset, we selected 1,427 participants aged 65 or older who without missing data. One-way batch analysis was used to determine the difference of handgrip strength according to the frequency of physical activity. If there was a difference between the groups, a post-test was conducted to confirm the statistical significance. The repeated measurement two-way ANOVA was performed to test mean difference between groups and measurements, and the effect of interactions between them on the significant level of $a=.05$.

RESULTS The handgrip strength was higher in participants who reported higher physical activity frequency. In addition, the elderly women who participated in the higher moving place physical activity and walking exercise, and the elderly men who participated in the higher resistance training exercise, the handgrip strength was significantly higher.

CONCLUSIONS We found that the higher frequency of physical activity may associated with higher handgrip strength in Korean elderly. However, because we did not consider the difference of total volume of physical activity in each group, further study is needed.

(c) The Asian Society of Kinesiology and the Korean Academy of Kinesiology

서론

우리나라 고령인구 비율은 2019년 14.9\%로 증가하 고 있으며, 2060년에는 65세 이상 구성비가 43.9\%로 증가되어 초고령 사회로 진입할 것으로 추정하고 있다 [1]. 현대 사회에서 노인 인구 비율이 확대되어 건강한 노년 삶에 대한 관심이 증가되고 있으며[2], 이러한 건 강한 노인의 삶을 지속하기 위해서는 규칙적인 신체활 동으로 체력을 증가시킬 수 있다고 보고 되었다[3]. 65 세 이상 노인의 경우 일주일에 150 분 이상 중강도 신체

*Correspondence: Keun-Ok An, Korea National University of Transportation, 50 Daehak-ro, Chungju-si, Chungbuk, Republic of Korea; Tel: +82-043-841-5995; E-mail: koan@ut.ac.kr
활동 또는 75 분 이상 고강도 신체활동을 할 것과 근력 강화 신체활동은 주 2 일 이상으로 권장하고 있다[4].

신체활동에 따른 유익한 효과를 얻기 위하여 일정한 수준의 참여 정도를 의미하는 중강도 신체활동과 고강도 신체활동이 있다[5]. 하지만 노인들에서는 신체활동이 건강증진에 있어 긍정적인 효과를 주는 것을 인식하지 만 부상과 체력 저하로 신체활동 참여율이 감소하거나 저강도 신체활동을 선택하게 된다[6]. 또한 노인의 경우 주당 1 회조차도 신체활동을 하지 않는 비율이 약 $50.0 \%$ 이상이나 된다는 점은 문제점으로 인식 될 수 있다[7].

노인의 신체활동 참여가 감소하게 되면 근육량 및 근력의 저하로 나타나게 되며, 일상생활에 필수적인 체 력 수준이 떨어지게 된다[8]. 특히 비활동적인 사람에 
게서 급격한 근력 감소가 나타나며 노인의 근력 저하는 신체활동 장애로 이어지게 된다. 근력을 향상시키는 것 이 노인의 건강을 유지하는데 바람직하다고 보고되고 있다[9-11]. 일반적으로 노인의 건강을 향상시키기 위 하여 기초적인 근력을 향상시키는 것이 바람직하다고 보고 되고 있으며, 근력을 향상시키기 위해서는 다양한 활동을 통하여 근육을 자극해야 한다[9].

그 중 악력은 감각기관 및 의사 표현 기관으로도 사용 되기도 하며, 나이가 증가할수록 저하되기 때문에 일상 생활 수행에 불편함이 발생된다고 보고한 바 있다[12]. 또한 노인들의 악력은 신체 균형과 더불어 기능적 장애 정도와 팔다리 근력을 예측할 수 있는 쉽고 빠른 하나 의 대안일 수 있다[13]. 악력은 신체 건강을 비롯한 삶 의 다양한 영역과 관련이 있으며, 노인의 악력은 근육 감소로 인한 신체적 건강 상태를 나타낸다[14]. 최근 연 구에서는 악력이 높을수록 남녀 모두에 게서 대사증후군 위험률이 감소하는 것으로 나타났으며, 노인에 있어서 낮은 악력을 유지 할 경우 인지기능의 감소와 관련성이 있는 것으로 보고되고 있다 $[15,16]$. 또한, 유럽 및 아 시아 근감소증 연구위원회에서는 악력을 근감소증 및 노쇠를 진단하는 지표로 활용하고 있다.

높은 악력을 유지하고 향상시키기 위해서 평상시 고 강도 운동, 근력 운동 등 신체활동을 적극적으로 참여함 으로 향상시킬 수 있으며, 운동강도와 빈도도 평균 3일 이상인 노인에게서 높게 나타난다고 보고 되었다[17]. 또한 신체활동 참여 빈도가 높은 노인에게서 높은 악력 이 나타나는 결과를 뒷받침하고 있으며, 악력을 유지하 는 것은 건강유지와 직결된 문제라 할 수 있기 때문에 평상시 약력을 유지하고 증가시키기 위해서 신체활동 을 실천하는 것이 필수적인 요소라 할 수 있겠다[18].

노인의 신체활동과 관련된 연구에서는 총 신체활동 량(MET)을 활용한 복부비만, 좌식시간, 근육량, 대사증 후군 등의 연구가 발표되고 있다[19, 20]. 선행연구에 서는 1 주일간 총 활동량을 통한 신체활동 정도를 평가 하지만 노인에게 있어서 체력 저하로 인한 참여율과 주 당 1 회 조차도 신체활동을 하지 않는 비율이 $50.0 \%$ 이 상이나 된다는 점에서 노인 신체활동 참여 빈도에 따른 근력에 관련된 연구는 미흡한 실정이다.

본 연구에서는 국민건강영양조사 원시 자료를 이용 하여 노인의 신체활동 유형별 참여 빈도에 따라서 악력 의 차이를 규명하고 노인에게 있어서 신체활동과 악력
의 관련성을 파악하고자 한다.

\section{연구방법}

\section{연구자료 및 대상자 선정}

본 연구는 질병관리본부에서 전국 규모로 매년 실 시하고 있는 국민건강영양조사 제 7기 2017년도 자료 를 이용하여 조사에 참여한 8,127 명 중 만 65세 이상 1,671 명을 분류하였고, 그 중 신장 $(\mathrm{cm})$, 체중 $(\mathrm{kg})$ 및 신 체활동 설문지에 결과가 누락된 대상자를 제외하였다. 또한 3 차례의 주동 손의 악력 측정 시 1 회이상 측정치가 있는 대상자를 선정하였으며, 최종적으로 만 65세 이상 남녀 노인 1,427 명을 대상으로 분석하였다.

\section{연구내용 및 관련 지표}

1) 신체계측

본 연구에서는 신체계측 자료로 신장 $(\mathrm{cm})$, 체중 $(\mathrm{kg})$ 자료를 사용하였다.

2) 주당 신체활동 일수

신체활동 정보는 국제신체활동설문지 (Global Physical Activity Questionnaire; GPAQ)를 이용하여 여가 중강도 신체활동, 장소이동 신체활동, 걷기 일수, 근력운동 일수 등으로 조사하였다. 이중 원시자료를 이 용하여 활동의 강도와 주당 활동일수 및 시간(분)중에 주당 활동일수만을 사용하였다. 주당 활동일수는 참여 횟수에 따라서 A-Group(운동안함), B-Group(1 3회), C-Group(4 5회), D-Group(6 7회)으로 사용하였고 [7], 신체활동 중 근력운동 일수는 A-Group(운동안함), B-Group(1 2회), C-Group(3 4회), D-Group(5회 이 상)으로 사용하였다[21].

\section{3) 악력측정}

국민건강영양조사에서는 악력 근력분포를 파악 하기 위해서 디지털 악력계(Digital grip strength dynamometer, T.K.K 5401, Japan)를 이용하여 악력검 사를 측정하였다. 이 측정한 값의 양손 $1,2,3$ 차 측정치 중 주동 손의 최대값을 사용하였다. 본 연구에서는 악력 (악력[kg]/체중[kg] x 100,\%)으로 정의하였다[22]. 4) 자료처리

제 7기 2017년도 국민건강영양조사를 이용하여 연 구의 대상자의 일반적인 특성을 평균과 표준편차로 나 타냈으며, 신체활동 유형별 참여에 따른 주동 손의 악 력 최대값을 정규성 만족여부에 따라 일원배치분산분석 
과 비모수를 이용하였다. 집단 간 차이가 존재하는 경우 사후검증(Scheffe-test)을 실시해 유의성을 확인하였으 며, 유의수준은 $\mathrm{p}<.05$ 로 설정 하였다.

\section{결과}

\section{연구대상}

본 연구의 자료는 국민건강영양조사 제7기 2017년 원시자료를 이용하여 총 참여자 8,127 명 중 만 65 세 이 상 남녀로 신체활동과 악력 등 설문지에 결과가 누락된 대상자를 제외한 1,427 명을 최종분석 사용하였다. 조 사대상자의 신체적 특성 및 주동 손 악력의 최대값은 $<$ Table 1 >과 같다.

Table 1. Subject's physical characteristics and handgrip strength

\begin{tabular}{lccc}
\hline & $\begin{array}{c}\text { M } \\
(\mathbf{n}=\mathbf{6 2 4})\end{array}$ & $\begin{array}{c}\mathbf{F} \\
(\mathbf{n = 8 0 3})\end{array}$ & Total \\
\hline $\begin{array}{l}\text { Age } \\
\text { (year) }\end{array}$ & $72.65 \pm 4.92$ & $72.89 \pm 5.17$ & $72.78 \pm 5.06$ \\
$\begin{array}{l}\text { Height } \\
(\mathrm{cm})\end{array}$ & $165.38 \pm 5.58$ & $151.67 \pm 5.75$ & $157.66 \pm 8.85$ \\
$\begin{array}{l}\text { Weight } \\
\text { (kg) }\end{array}$ & $64.44 \pm 9.03$ & $56.41 \pm 8.44$ & $59.91 \pm 9.56$ \\
$\begin{array}{l}\text { Hand strength } \\
\text { \%) }\end{array}$ & $50.50 \pm 10.76$ & $34.60 \pm 8.87$ & $41.54 \pm 12.53$ \\
\hline
\end{tabular}

\section{노인의 신체활동 유형별 참여 현황}

대상자의 신체활동 유형별 참여 현황은 <Table 2> 와 같다. 신체활동 유형별 주간 참여빈도에 따른 조사결 과 중강도 신체활동은 전혀 하지 않은 A-Group 대상 자가 대부분 이였다. 장소이동 신체활동은 남녀 대상자
모두 전혀 하지 않는 A-Group이 가장 많았으며, 남녀 모두 참여빈도는 B-Group, D-Group, C-Group 순으 로 나타났다. 걷기 일수는 남자가 D-Group, B-Group, A-Group, C-Group 순으로 나타났으며. 여자는 AGroup, D-Group, B-Group, C-Group 순으로 나타났 다. 근력운동 일수는 남녀 대상자 모두 전혀 하지 않 는 A-Group이 가장 많았으며, 남녀 모두 D-Group, C-Group, B-Group 순으로 나타났다.

\section{노인의 신체활동 유형별 참여에 따른 악력}

노인의 신체활동 유형별 주간 참여 빈도에 따른 악력 의 차이는 <Table 3 >과 같다. 중강도 신체활동에서는 남녀 노인 모두 A-Group 보다 다른 Group에서 높은 악 력 \%가 보이며 유의한 차이는 나타나지 않았다. 신체활 동을 하지 않은 Group보다 신체활동에 참여하는 Group 이 수치적으로 높은 악력 \%를 보여 주는 것으로 나타 났다. 장소이동 신체활동에서는 남자 노인이 C-Group 에서 $52.5 \pm 9.8 \%$ 로 가장 높은 높은 수치로 나타났다. 여자 노인에게서는 유의한 차이가 나타났으며 $(\mathrm{p}<.05)$, 사후검증 결과 D-Group이 36.7 $\pm 8.2 \%$ 로 A-Group에 $33.9 \pm 9.2 \%$ 보다 높게 나타났다. 걷기 일수에서는 남 자 노인이 C-Group에서 $52.4 \pm 10.0 \%$ 로 가장 높은 수 치로 나타났다. 여자 노인에 게서는 유의한 차이가 나타

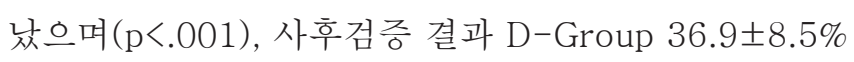
와 B-Group 34.8土8.7\%이 A-Group 32.3土9.2\% 보 다 높게 나타났다. 근력운동에서는 남자 노인이 유의한 차이가 나타났으며 ( $\mathrm{p}<.001)$, 사후검증 결과 D-Group $54.8 \pm 10.0 \%$ 와 C-Group 54.1 $\pm 8.7 \%$ 이 A-Group $49.0 \pm 10.9 \%$ 보다 높게 나타났다. 여자 노인에게서는 유의한 차이는 나타나지 않았다.

Table 2. Activity participation prefecture by physical activity type of the elderly

\begin{tabular}{|c|c|c|c|c|c|c|}
\hline & & A-Group & B-Group & C-Group & D-Group & Total \\
\hline \multirow{2}{*}{$\begin{array}{l}\text { Moderate Intensity } \\
\text { Physical Activity }\end{array}$} & M & 524 & 39 & 32 & 29 & \multirow{8}{*}{$\begin{array}{r}M=624 \\
F=803 \\
n=1,42\end{array}$} \\
\hline & $\mathrm{F}$ & 737 & 41 & 18 & 7 & \\
\hline \multirow{2}{*}{$\begin{array}{l}\text { Move place } \\
\text { Physical Activity }\end{array}$} & M & 317 & 126 & 71 & 110 & \\
\hline & $\mathrm{F}$ & 406 & 173 & 99 & 125 & \\
\hline \multirow{2}{*}{$\begin{array}{l}\text { Walking } \\
\text { Exercise }\end{array}$} & M & 136 & 154 & 102 & 232 & \\
\hline & $\mathrm{F}$ & 261 & 218 & 101 & 223 & \\
\hline \multirow{2}{*}{$\begin{array}{l}\text { Resistance Training } \\
\text { Exercise }\end{array}$} & M & 438 & 33 & 54 & 99 & \\
\hline & $\mathrm{F}$ & 733 & 14 & 22 & 34 & \\
\hline
\end{tabular}




\begin{tabular}{|c|c|c|c|c|c|c|c|c|}
\hline & \multicolumn{2}{|c|}{$\begin{array}{l}\text { Moderate Intensity } \\
\text { Physical Activity }\end{array}$} & \multicolumn{2}{|c|}{$\begin{array}{c}\text { Move place } \\
\text { Physical Activity }\end{array}$} & \multicolumn{2}{|c|}{$\begin{array}{l}\text { Walking } \\
\text { Exercise }\end{array}$} & \multicolumn{2}{|c|}{$\begin{array}{l}\text { Resistance Training } \\
\text { Exercise }\end{array}$} \\
\hline & $M$ & $\mathbf{F}$ & M & $\mathbf{F}$ & M & $\mathbf{F}$ & $\mathbf{M}$ & $\mathbf{F}$ \\
\hline A-Group & $50.11 \pm 10.90$ & $34.33 \pm 8.80$ & $49.93 \pm 11.06$ & $33.90 \pm 9.18$ & $49.61 \pm 11.80$ & $32.31 \pm 9.15$ & $49.00 \pm 10.87$ & $34.42 \pm 8.90$ \\
\hline B-Group & $52.66 \pm 10.37$ & $37.55 \pm 9.45$ & $50.09 \pm 10.85$ & $34.38 \pm 8.50$ & $49.37 \pm 10.09$ & $34.82 \pm 8.71$ & $51.73 \pm 9.90$ & $37.38 \pm 8.62$ \\
\hline C-Group & $52.47 \pm 8.34$ & $36.61 \pm 9.22$ & $52.53 \pm 9.80$ & $35.19 \pm 8.66$ & $52.40 \pm 10.00$ & $35.03 \pm 8.01$ & $54.05 \pm 8.70$ & $36.84 \pm 9.10$ \\
\hline D-Group & $52.46 \pm 10.74$ & $38.99 \pm 8.37$ & $51.32 \pm 10.28$ & $36.72 \pm 8.21$ & $50.94 \pm 10.79$ & $36.87 \pm 8.46$ & $54.81 \pm 10.00$ & $35.93 \pm 7.85$ \\
\hline$p$ & .232 & .050 & .238 & .016 & .103 & .000 & .000 & .277 \\
\hline Post-hoc & & & & $A<D$ & & $A<B, D$ & $A<C, D$ & \\
\hline
\end{tabular}

Hand strength : Hand strength $(\mathrm{kg}) /$ Weight $(\mathrm{kg}) \times 100, \%$

\section{논의}

본 연구에서는 신체활동 유형별 주간 참여 빈도에 따 른 악력에 차이를 확인 하였으며, 신체활동이 악력에 밀 접한 관련이 있다는 것을 확인하였다.

연구 결과에서 노인들은 중강도 신체활동 참여가 낮 았으며, 신체활동을 많이 참여할수록 높은 악력을 보였 다. 하지만 노인들은 연령이 증가하고 체력이 저하되어 신체활동 참여율이 감소하거나 중강도 신체활동 보다는 저강도 신체활동을 참여하고 있는 것을 보여준다. 특히 노인들의 경우 격렬한 운동을 수행하기 어려워 중강도 이상의 신체활동을 수행하기 어렵다. 노인들은 신체활 동을 하는 것만으로도 건강 유지에 긍정적인 영향을 주 며, 운동 주당 참여빈도에 따라 근력에 영향을 주는 것 으로 보고하였다 $[6,7,23]$. 남녀 노인 모두에게서 신체 활동을 참여하는 것만으로도 신체활동을 하지 않는 것 보다 높은 악력 수치가 나타났다.

장소 이동 신체활동과 걷기 일수에 따른 악력 차이 에서는 여자 노인에게서 유의한 차이를 보였다. 2017 년 노인실태조사 보고서에 따르면 노인들의 주된 운동 종류는 걷기가 $71.1 \%$ 로 가장 높았고, 그 다음 체조(맨 손체조 및 생활체조), 자전거(실내), 등산, 헬스, 수영 순 으로 나타났다. 성별에 따른 걷기 실천에서 남자 노인이 $68.7 \%$, 여자 노인이 $74.0 \%$ 로 여자 노인 걷기 신체활 동에서 높은 수치를 보였다[24]. 또한 노인들의 일주일 간 걷기 활동 수행현황에서 이동 목적 빈도 및 시간, 운 동 목적 빈도 및 시간이 남자 노인보다 여자 노인이 높 게 나타났다[25]. 이처럼 남자 노인에 비해 여자 노인이 걷기 관련 신체활동에서 실천 정도와 빈도 시간 모두 높
은 참여를 보였으며, 장소이동 신체활동과 걷기 일수를 참여한 Group에서 높은 악력 수치를 보였다.

근력운동과 악력 차이에서는 남자 노인이 유의한 차 이를 보였다. 2017년 노인실태조사 보고서에서 따르 면, 노인 성별에 따른 운동실천 정도 중 보디빌딩과 헬 스, 자전거(실내), 지상레저스포츠(등산/빙상) 등 근력 과 관련된 운동에서 남자 노인이 높은 참여율을 보였다 [24]. 본 연구에서도 신체활동 참여 비율은 남자 노인 이 여자 노인보다 높게 나타났으며, 근력운동을 하는 것 이 하지 않은 Group에 비해 높은 악력 수치를 보였다.

본 연구에서 국민건강영양조사를 이용하여 노인들 의 신체활동에 따른 악력에 차이를 규명하였다. 노인의 특성상 격렬한 운동을 수행하기 어려워 중강도 이상의 신체활동을 참여하기 어렵다. 노인의 신체활동과 악력 에 깊은 관련성이 있으며, 노인의 특성을 고려한 신체 활동이 규명되어 근력 향상과 건강한 생활이 가능할 것 으로 생각된다.

국민건강영양조사에서는 전국민을 대상으로 설문지 통한 조사가 이루어졌기 때문에 많은 대상자를 선정할 수 있는 장점이 있었으며, 반대로 실험연구에 기반을 두 지 않아 정확한 분석변인을 설정하기 어려웠다. 차후 신 체활동 빈도와 악력에 관계에 따른 실험연구를 통해 노 인들의 특성을 고려한 신체활동과 악력의 관계에 대한 연구가 진행되어야겠다.

\section{결론}

본 연구에서는 국민건강영양조사를 이용하여 남녀 노인 1,427 명에 대한 신체활동 유형별 참여에 따른 악 
력의 차이를 분석한 결론은 다음과 같다.

첫째, 중강도 신체활동은 노인의 높은 악력에 영향 을 보이지만 노인의 특성상 격렬한 운동을 수행하기 어 려워, 신체활동을 참여하는 것만으로도 하지 않는 것보 다 높은 악력을 보이는 것으로 생각된다.

둘째, 장소 이동 신체활동과 걷기에서는 여자 노인이 참여 빈도가 높을수록 높은 악력 차이를 보였다.

셋째, 근력운동은 남자 노인이 여자 노인에 비해 주 당 높은 참여를 보이고 있으며 근력운동이 악력에 영향 을 주는 것으로 나타났다.

\section{Conflicts of Interest}

The authors declare no conflict of interest.

\section{References}

1. Statistics Korea. Statistics of the elderly. 2019; http://kostat. go.kr/portal/korea/kor_nw/1/1/index.board.

2. Baek SK, Yeom DS, Seo JK. The influence of health promoting behavior on expectation emotion and social connectivity in the elderly physical education participants. Koreasn Journal of Sport. 2019; 17(1):171180.

3. Kwak KI, Baek CH, Ryu SY. Relationship between the physical activity levels and health care utilization in korean elderly. Korea Academy Industrial Coopertation Society. (2015); 16(1):617-626.

4. Seo YM, Kang MS, Jeon MY. Predictive factors on level of physical activity in the community dwelling elderly. Journal of the Korea Convergence Society. 2016; 7(6):151-160.

5. Koo KM, Kim CJ. Analysis of ecological factors of older adults participating in moderate to vigorous physical activities. Journal of Adapted Physical Activity and Exercise. 2018; 26(3):67-83.

6. Moon HJ, Lee IS. Gender-based comparison of physical activity levels of older korean adults with chronic disease. J Korean Gerontol Nurs. 2011; 13(2):120-130.

7. Jung HS, Lee BK. The difference of blood lipid and cognitive ability among female elderly people according to their physical exercise frequency. Korean Journal of Sport.
2017; 15(3):545-552.

8. Lee IH, Kang HS. Association of health physical fitness and serum vitamin $\mathrm{D}$ with global cognitive performance in older persons. Ksles. 2016; 23(2):217-224.

9. Chung JS. Effect of leg strength on flexibility, balance and gait characteristics in elderly woman. The Korean Journal of Growth and Development. 2011; 19(3):233239.

10. Liu CJ, Latham NK. Progressive resistance strength training for improving physical function in older adults. Cochrane Database Syst Rev. 2009; 8(3):2759-2768.

11. Nair KS. Aging muscle. The Am J Clin Nutr. 2005; 81(5):953-963.

12. Lee KS, Woo KJ, Shim JH, Lee GH. The clinical study of grip and pinch strength in normal korean adult Journal of the Korean Orthopaedic Association. 1995; 30(6):1589-1597.

13. Lee HS, Lee CH. The effect of progressive resistance training with elastic band on grip strength and balance in middle elderly women. J Kor Phys Ther. 2013; 25(2):110-116.

14. Chung JY, Lee JW, Im JY, Lee DC. Hand grip power is independently associated with physical function in community dwelling elderly. Korean J Clin Geri. 2010; 11(4):315-323.

15. Cho JK, Yoon ES, Park SH. Association of relative handgrip strength with the incidence of metabolic syndrome in korean adults: a community based cohort study. Exercise Science. 2019; 28(3):303-310.

16. Choi MJ, Kim GY. The effects of relative handgrip strength on cognitive function: the moderating roles of paid employment status and social activities. Journal of the Korea Gerontological Society. 2019; 39(3):549-567.

17. Lee JA. Relationship between grip strength and prevalence of hypertension in korean adults: the sixth korea national health and nutrition examination survey 2015. Asian J Kinesiol. 2017; 19(3):53-60.

18. Taekema DG, Gussekloo J, Maier AB, Westendorp RG, de Craen AJ. Handgrip strength as a predictor of functional, psychological and social health. A prospective population-based study among the oldest 
old. Age Ageing. 2010; 39(3):331-337.

19. Hwang SH, Yu MS, Jeon JY. Impact of central obesity and physical activity behavior on health-related quality of life among korean older adults. Korean Journal of Sport Studies. 2018; 57(4):375-386.

20. Jung DH, Kim JH. Relationships among muscle mass and obesity, metabolic syndrome, physical activity, and nutrient intake in elderly women: based on the 4 th5th (2008-2011) korean national health and nutrition examination survey. Korean J Community Living Sci. 2018; 29(4):469-483.

21. Son JA. An analysis of factors related with sarcopenia and sarcopenic obesity in the elderly using 2008-2011 Korean National Health and Nutrition Examination Survey. Yeungnam University graduate school, Yeong nam. Republic of Korea. 2018.

22. Lee,O, Kim YS. Association between Grip Strength as Diagnostic Criteria of Sarcopenia and Health-Related Quality of Life in Korean Elderly. Korean J Sports Med. 2018; 36(1):15-23.

23. Lee KH, Choi JW, Lee NE, et al. Relationship between health-related physical fitness, cognitive function and isolation in the elderly. Journal of the Korea Convergence Society. 2018; 9(4):285-301.

24. Ministry of Health and Welfare. Elderly status report 2017. 2017; http://www.mohw.go.kr.

25. Lee HS, Ahn JS, Chun SH. Analysis of environmental correlates with walking among older urban adults. Journal of the Korean Institute of Landscape Architecture. 2011;39(2):65-72. 